\title{
A Solution of the Container Stacking Problem by Genetic Algorithm
}

\author{
Phatchara Sriphrabu, Kanchana Sethanan, and Banchar Arnonkijpanich
}

\begin{abstract}
This paper proposes a developed simulation model for stacking containers in a container terminal through developing and applying a genetic algorithm (GA) for containers location assignment with minimized total lifting time and increased service efficiency of the container terminals. The application obtained from the genetic algorithm shows the appropriate containers location assignment based on the arrival of containers at a container terminal and correlates it with the order of the containers loaded onto container ships. The solutions from the genetic algorithm were used in the model application. Observations were made on container total lifting time using the simulation model based on a genetic algorithm for finding the best configuration of containers in a bay and the solution of simulation based on the First-In, First-Storage (FIFS) rule. Experimental results showed that the simulation model based on the genetic algorithm is more efficient than the simulation model based on the FIFS rule.
\end{abstract}

Index Terms-Stacking container, genetic algorithm, simulation model.

\section{INTRODUCTION}

The marine shipping industry is the main infrastructure for international trading. It is an important industrial sector that enhances potentiality as well as efficiency of economic development. Also, the industry provides employment and brings a great deal of foreign currencies into a country. Thailand relies on marine shipping for 95 percent of its international trade, most of which involves containerization. Goods are first loaded into containers, which are in turn transported to a container terminal and onto a container ship. In this paper, the steps in moving containers from container yard to container ship are generally operation. The containers arrive at the container yard in the container terminal by truck. A yard crane (YC) then lifts containers one by one from the trucks and places them in the container yard. When a container ship arrives at the quayside of a container terminal, the yard crane lifts the container at the container yard and unloads onto the truck. Next, the truck carries the container to the quayside. A quay crane (QC) lifts the container and unload it onto the container ship. The steps are repeated until all containers are moved. It can be seen that containers' location assignment at the container terminal correlates to the stowage plan for a container ship: if the first container to be laid onto the container ship has been placed at the bottom in

Manuscript received June 8, 2012; revised September 12, 2012.

P. Sriphrabu and K. Sethanan are with the Industrial Engineering Department, Khon Kaen University, Khon Kaen, 40002 Thailand (e-mail: p.sriphrabu@gmail.com, ksethanan@gmail.com).

B. Arnonkijpanich is with the Department of Mathematics, Khon Kaen University, Khon Kaen, 40002 Thailand (e-mail: abanchar@kku.ac.th). the yard, for example, then the containers on top of it have to be removed first. This causes an inefficient condition known as double handling, which impacts operations both in terms of time and cost to the container terminal.

Container stacking is a major problem at a container terminal because the container location assignment affects the operating time of the container terminal, which operates continuously. Therefore, if there is a ceasing of operation at any point, it retards operations at other points. The container stacking problem is caused by the uncertainty in the arrival of a container at the container terminal. Thus, container stacking is planned at most ports on a day-by-day basis. When containers reach the container terminal, the container terminal has to find a position that correlates to the order of container lifting and placing onto the container ship to avoid double handling. This paper proposes a simulation model for container lifting in order to minimize the lifting time. A genetic algorithm was then applied to containers' location assignment to minimize the lifting time.

\section{LITERATURE REVIEW}

The container stacking problem in a container terminal is an important part of port management. Thus, container terminal operations have been of increasing interest to researchers. This article studies the most important process at a container terminal that can be optimized by means of operation research.

Relocation is most important to storage and pickup operation in block stacking because it affects the handling cost. Thus, a heuristic rule for relocating blocks to minimize the number of relocation during pickup operation is one method used to solve the container storage problem. Therefore, determining the locations of relocated blocks can be divided into two methods: a branch-and-bound (B\&B) algorithm and a decision rule [1]. In addition, the layout of the container yard is an important factor in the efficiency of storage in a container terminal, in which loading and unloading of containers on the stack is performed by yard cranes or transfer cranes. Thus, designing the layout of container yards where transfer cranes and yard trucks are one method used for container stacking is a problem [2]. In container terminals, a block size is the unit of storage space inside the container yard. The block size affects yard crane operation and productivity. Lee and Kim [3] proposed two methods for optimizing the block size in container yards, by the design block layout to determine the number of bays in a block, the number of rows in a bay, and the number of tiers.

Usually, the stowage planning determines the order the containers are loaded onto the container ship. Therefore, 
some researchers study the pre-marshalling process in a yard. Lee and Chao [4] proposed a developed model for planning the moving of containers at bay. The heuristic proposed comprised a neighborhood search process, an integer programming model, and three minor subroutines. Imai et al. [5] presented a solution to rehandle containers in the yard and to plan loading onto a container ship for multi-objectives simultaneous stowage because the efficiency of a container terminal depends on the smoothness of the container-transferring equipment. Ambrosino et al. [6] presented a heuristic approach to reduce the relationships between the model and the pre-stowage rules so that the solution of the combinatorial optimization problem can start. They divided the set of usable positions on the container ship into different subsets. The stowage of containers on the ship depends on the pattern and operations in container movement.

In container terminals, some researchers have developed a simulation model to analyze the operation of container terminals. Shabayek and Yeung [7] proposed a model (using Witness software) to simulate Kwai Chung container terminals. The objective was to investigate the extent to which the simulation model could predict the actual container terminal operations with a high order of accuracy. Yun and Choi [8] proposed a simulation model for a container terminal system analysis. The container terminal consists of a gate, a container yard, and a berth. The facilities used in the container terminal are transfer cranes, gantry cranes, trailers, and yard tractors. The simulation model has been developed using an object-oriented approach and SIMPLE++ programming. McLea and Biles [9] simulated the transferring situation of multiple shipping lines and schedules in order to determine the appropriate cost and operations of the lines and the total impact from the servicing schedules.

Review of past studies reveals a lot of research into the problems at container terminals. Both optimization models and simulation models have been used in these studies. However, managerial problems at container terminals are new with little existing research, especially regarding the container stacking problem at container terminals where meta-heuristic, an optimization technique, is used in the planning of container stacking through a simulation model.

\section{METHOD AND PROCEDURE}

This research relied on the development of a simulation model for the operation of the container terminal based on the Arena program. A genetic algorithm has been developed by software in order to determine an appropriate solution for container stacking. The research method included two implementation parts: 1) creating a simulation model and 2) creating a genetic algorithm. The solution obtained from the genetic algorithm was used as an input to the simulation model for lifting containers at the container terminal. The experimental results show the time consumed in each container lift and placement onto the container ship. The timed results from the genetic algorithm and FIFS rule were compared. The input-output data for the simulation model are shown in Fig. 1.

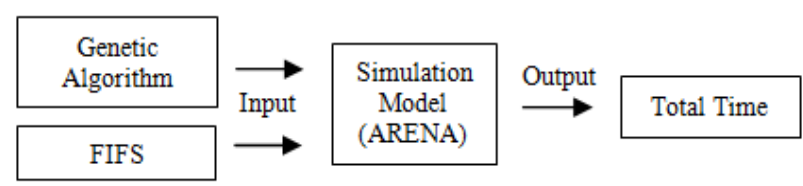

Fig. 1. Input - output data of simulation model.

The slot numbers for container stacking have been set with the time spent on each lift for each slot as shown in Fig. 2. There were 3 tiers and 4 stacks of containers. The lifting time was set according to the movement of the yard crane. For example, if a container at slot no. 3 was to be lifted, the lifting time was set at 4 units, etc.

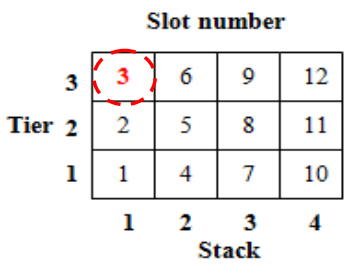

Slot number

\begin{tabular}{|c|c|c|c|c|}
\hline 3 & 3 & 6 & 9 & 12 \\
\hline Tier 2 & 2 & 5 & 8 & 11 \\
\hline \multirow[t]{2}{*}{1} & 1 & 4 & 7 & 10 \\
\hline & 1 & $S$ & $\begin{array}{r}3 \\
\text { ack }\end{array}$ & 4 \\
\hline
\end{tabular}

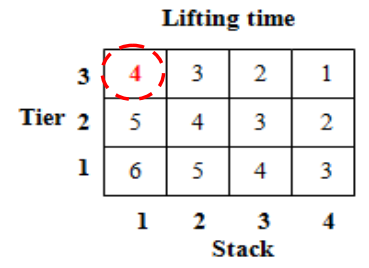

Lifting time

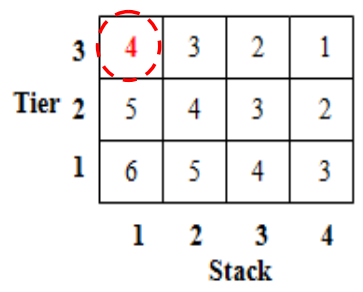

Fig. 2. Slot numbers and lifting time in each slot.

The time a truck spent transferring a container from the container yard to the quayside was surveyed in the real situation with an analysis conducted on the distribution of data using the input analyzer function.

\section{A. Simulation Model}

The simulation model is the process of model development to study the behavior of a system. It enables us to study the impact from changes and reduce the risk that might occur in a real situation. It also allows us to measure the capabilities of different alternatives of the system being designed [10]. This assists in a strategic problem, rather than a practical one, and provides a tool for change management.

The objective of developing the simulation model for stacking containers at a container terminal was to determine the time a yard crane spent to lift a container and transfer it to the container ship. The excel program was used for acquiring the input-output data. The input data of the simulation model included the container numbers in the order of the slot numbers for stacking, whereas the output data was the time spent for lifting each prioritized container onto the container ship. The procedure of the simulation model was divided into four parts as shown in Fig. 3. Part 1 involved stacking or storing containers in the container yard according to their slots. Part 2 was lifting containers, which had to be executed in the order of the loading of the containers onto the container ship. Part 3 was the transferring of the containers to the quayside. Part 4 was the unloading of the containers onto the container ship. 


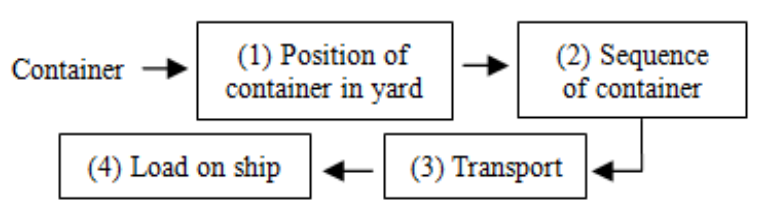

Fig. 3. Procedures in developing the simulation model.

The simulation model consisted of two main parts, the module and the animation (Fig. 4).

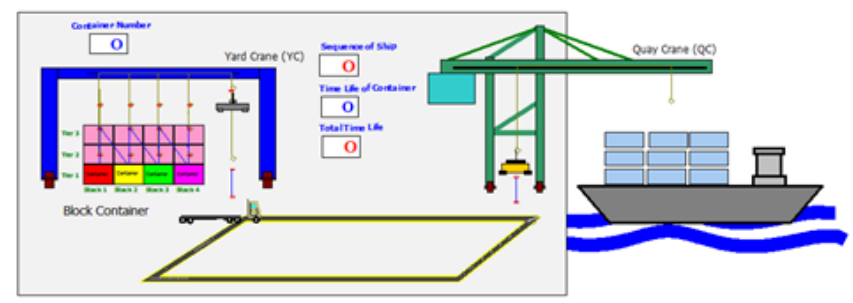

Fig. 4. Animation built by the Arena program.

\section{B. Genetic Algorithm}

The genetic algorithm is a means for finding a solution by simulating natural and genetic operations through sampling a group of a population as the initial population. Biological processes are applied, namely the selection process, the crossover process, and the mutation process in order to determine the solutions from interactions among the group population until new groups emerge. For each generation, the best solution is recorded. This development is repeated until all of the designated groups are operated on. The final best solution from the genetic algorithm is derived by comparing the best solutions of all batches. The genetic algorithm procedures are shown in Fig. 5.

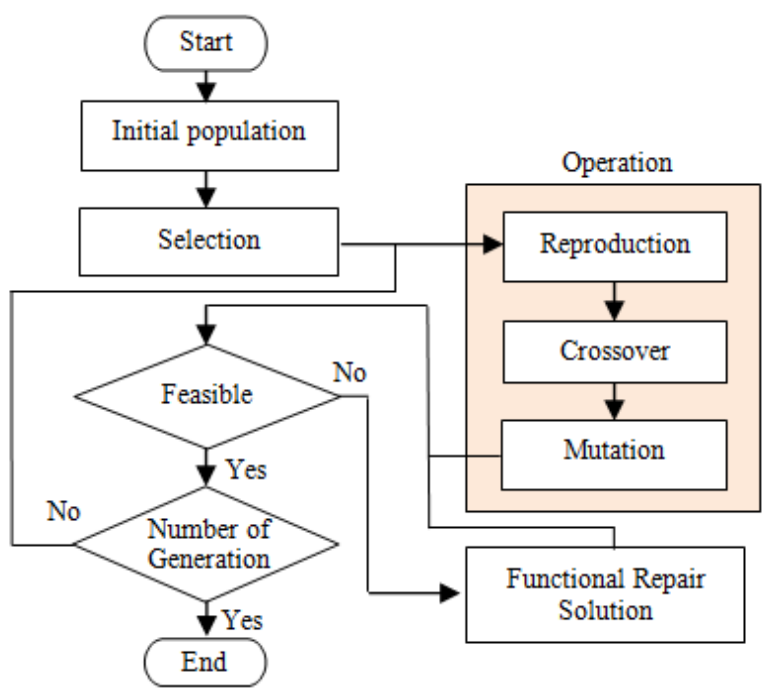

Fig. 5. Chart showing the structure and method of the genetic algorithm.

1) Initial Population: Determining the initial solution to the problem in this study involved developing the initial chromosome of the positioning of 12 container slots. The positions were modified into a chromosome pattern. One chromosome stands for the number of all of the slots in the bay, and genes are the number of the slots as shown in Fig. 6.

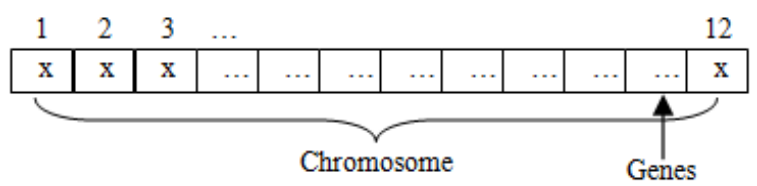

Fig. 6. Example of chromosome replacing containers positioning.

\section{Notations}

$i=$ Number of container to be lifted $(i=1,2, \ldots, n)$

$s \quad=\quad$ Slots number $(s=1,2, \ldots, k)$

$j \quad=\quad$ Case lifting time for container $(j=1,2, \ldots, N)$

$T_{s j} \quad=\quad$ Lifting time for container at slot $s$ case $j$

$n=$ Number of cases of container lifting

$N=$ Number of all containers

$k=$ Number of all slots

$X, Y, Z=$ Order numbers for container lifting

$t_{1} \quad=\quad$ Time used to lift containers at tier 3 of stack

$t_{2}=$ Time used to lift containers at tier 2 of stack

$t_{3}=$ Time used to lift containers at tier 1 of stack

when

$\begin{array}{lll}j=1 & j=2 & j=3 \\ X<Y<Z & Y>X<Z & Y<X<Z \\ X=t_{3}+t_{2}+t_{1} & X=t_{3}+t_{2}+t_{1} & X=t_{2}+t_{1} \\ Y=t_{2}+t_{1} & Y=t_{2} & Y=t_{3}+t_{2} \\ Z=t_{1} & Z=t_{1} & Z=t_{1} \\ & & \\ j=4 & j=5 & j=6 \\ Y>X>Z & Y<X>Z & X>Y>Z \\ X=t_{2}+t_{1} & X=t_{1} & X=t_{1} \\ Y=t_{1} & Y=t_{3}+t_{2} & Y=t_{2} \\ Z=t_{3} & Z=t_{3} & Z=t_{3}\end{array}$

The objective function values are calculated from the following equation:

$$
\text { Minimize } Z=\sum_{i=1}^{n} \sum_{s=1}^{k} \sum_{j=1}^{N} X_{i s j} T_{s j}
$$

Decision variable

$$
X_{i s j}=\left\{\begin{array}{l}
1, \quad \text { If container } i \text { is lifted at slot } s \\
\quad \text { with lifting time case } j \\
0, \quad \text { If others }
\end{array}\right.
$$

2) Reproduction: Reproduction is a process of chromosome selection that will yield the best solution for each generation to become the new generation. This assists the chromosome in developing the best solution in the next generation.

3) Crossover: Crossover is the matching of a genetic pair and mutating some of the genes in order to obtain new breeds that are based on the former genes. This may assist the chromosome in obtaining better solutions. This research was based on the two-point crossover method, which is the mutation of genes by selecting the crossing position between the two genes, a method known as partial matched crossover (PMX). The genes between the two points were mutated. Then the genes that were not similar to the mutated genes in the former position were copied. If there were similar genes, the positions between the chromosomes were compared and the genes were substituted as shown in Fig. 7. 


\begin{tabular}{|c|c|c|c|c|c|c|c|c|c|c|c|}
\hline \multicolumn{5}{|c|}{ 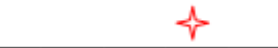 } & \multicolumn{7}{|c|}{ 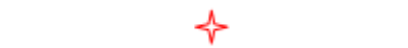 } \\
\hline 7 & 10 & 1 & 11 & 2 & 4 & 5 & 12 & 3 & 8 & 9 & 6 \\
\hline 1 & 10 & 2 & 7 & $\overline{4}$ & 3 & 8 & 5 & 11 & 12 & 6 & 9 \\
\hline 2 & 10 & 1 & $\overline{7}$ & $\overline{4}$ & 3 & 8 & $\overline{5}$ & 11 & 12 & 9 & $\overline{6}$ \\
\hline 1 & 10 & 7 & 11 & 2 & 4 & 5 & 12 & 3 & $\overline{8}$ & 6 & $\overline{9}$ \\
\hline
\end{tabular}

Fig. 7. Steps in crossover.

4) Mutation: The positions of genes on the same breed are swapped to obtain a new breed. The swapping technique used in this research involved sampling two genes in the same chromosome and then swapping their positions as in Fig. 8.

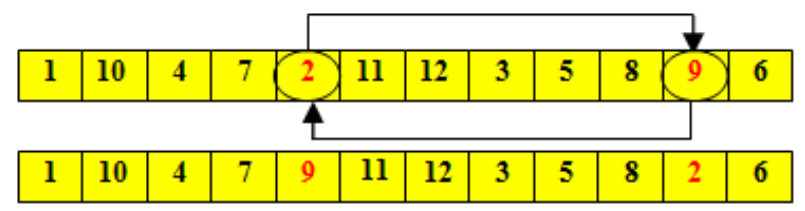

Fig. 8. Mutation procedure.

5) Chromosome Repair: The solutions obtained from the crossover or mutation procedures could turn out to be infeasible. For instance, the first arriving container should be placed in the lowest slot. Placing of containers is done in a stacking style; without a bottom container, no other containers can be placed at higher slots. Therefore, to ensure feasibility of container placement at a possible position, the solution has to be checked for accuracy according to the condition. Inaccurate solutions need to be adjusted by repairing the chromosome for a feasible solution.

\section{EXPERIMENTAL DESIGN AND RESULT}

Experiments were conducted in this study on ten samples using the Arena program for developing the simulation model and software to create the genetic algorithm that would lead to solutions. A computer with CPU 2.0 GHz. / 2.0 GB of RAM was used. The experimental results are shown in Table I

TABLE I: EXPERIMENTAL RESULT.

\begin{tabular}{ccccc}
\hline \multirow{2}{*}{ No. } & \multirow{2}{*}{ Problems } & \multicolumn{2}{c}{ Simulation } & \multirow{2}{*}{$\%$ Diff } \\
\cline { 3 - 4 } & & GA & FIFS & \\
\hline \hline 1 & $9-5-1-8-6-3-11-2-4-12-10-7$ & 43 & 44 & 2.27 \\
2 & $6-10-12-11-1-2-4-7-5-9-3-8$ & 43 & 64 & 32.81 \\
3 & $11-3-10-2-1-12-8-6-5-4-9-7$ & 42 & 55 & 23.64 \\
4 & $5-10-12-8-3-1-4-11-7-2-9-6$ & 42 & 63 & 33.33 \\
5 & $1-8-11-5-7-12-6-9-2-3-10-4$ & 45 & 69 & 34.78 \\
6 & $6-2-12-1-11-10-7-9-8-5-4-3$ & 42 & 62 & 32.26 \\
7 & $8-10-5-9-6-2-1-4-7-12-3-11$ & 44 & 53 & 16.98 \\
8 & $6-7-2-3-8-11-5-1-9-12-10-4$ & 47 & 59 & 20.34 \\
9 & $2-5-10-1-8-11-9-12-4-7-6-3$ & 44 & 66 & 33.33 \\
10 & $10-6-7-8-4-3-1-2-12-5-11-9$ & 42 & 56 & 25.00 \\
\hline \hline
\end{tabular}

\section{CONCLUSIONS}

A genetic algorithm is a means to find solutions from sampling groups of satisfactory solutions and then continuing to improve them from one generation to the next. The solutions therefore depend on the number of populations or solution groups sampled. If the number of populations is high, the solutions obtained are more satisfactory than those obtained from sampling a lower number of populations. Hence, increasing the number of solution chromosomes in each batch will increase the number of alternatives for solution chromosomes, and yield greater chances of obtaining better solutions. The increasing numbers of generations also raises the chances, in developing chromosomes, of producing better solution chromosomes. However, this means more time spent on computation.

The comparison between the solutions obtained from the genetic algorithm and the FIFS rule on ten sample problems under the simulation model shows that application of genetic algorithm is more efficient than the FIFS solution. It can be concluded that the use of a genetic algorithm to find initial solutions for simulation model inputs enables us to obtain better solutions than not finding initial solutions for simulation model inputs. This is due to the fact that the genetic algorithm is a meta-heuristic and allows sampling from groups of good solutions that can be improved to better solutions in the next generations. The efficiency of the simulation model is also increased as shown in Table 1 where the highest difference is $34.78 \%$ and the average is $25.47 \%$

Since the time spent in simulating the lifting of containers in this study is fixed, whereas in real situations, the time used in lifting containers at different positions may not be constant; there can be an impact on the operations in terms of time and cost. In addition, developing a simulation model that resembles true situations requires studies of constraints and factors related to time, transportation, and resources used in the system. Thus, the simulation model in this research is at an initial stage, with the aim to prove that positioning containers affects the operation time of the container terminal. Further studies should be conducted by increasing the area of container stacking as in a real situation at container terminals.

\section{ACKNOWLEDGMENT}

The anthers would like to thank for the Energy Management and Conservation Office and Graduate School, Khon Kaen University, Thailand.

\section{REFERENCES}

[1] K. H. Kim and G.-P. Hong, "A heuristic rule for relocating blocks," Computers and Operations Research, vol. 33, pp. 940-954, Apr. 2006.

[2] K. H. Kim, Y-M. Park, and M.-J. Jin, “An optimal layout of container yards," OR Spectrum, vol. 30, pp. 675-695, Nov. 2007.

[3] B. K. Lee and K. H. Kim, "Optimizing the block size in container yards," Transportation Research Part E, vol. 46, pp. 120-135, Jan. 2010.

[4] Y. Lee and S.-L. Chao, "A neighborhood search heuristic for pre-marshalling export containers," European Journal of Operational Research, vol. 196, pp. 468-475, Jul. 2009.

[5] A. Imai, K. Sasaki, E. Nishimura, and S. Papadimitriou, "Multi-objective simultaneous stowage and load planning for a container ship with container rehandle in yard stacks," European Journal of Operational Research, vol. 171, pp. 373-389, Jun. 2006. 
[6] D. Ambrosino, A. Sciomachen, and E. Tanfani, "Stowing a container ship: the master bay plan problem," Transportation Research Part A, vol. 38, pp. 81-99, Mar. 2004.

[7] A. A. Shabayek and W. W. Yeung, "A simulation model for the Kwai Chung container terminals in Hong Kong," European Journal of Operational Research, vol. 140, pp. 1-11, Jul. 2002.

[8] W. Y. Yun and Y. S. Choi, "A simulation model for container-terminal operation analysis using an object-oriented approach," Int. J. Production Economics, vol. 59, pp. 221-230, Mar. 1999.

[9] A. A. McLean and W. E. Biles, "A simulation approach to the evaluation of operational costs and performance in liner shipping operation," in Proc. 40th Winter Simulation Conference, Austin, 2008, pp. $2577-2584$

[10] D. W. Kelton, R. P. Sadowski, and D. T. Sturrock, Simulation with Arena, 4th ed., New York: McGraw-Hill , 2003

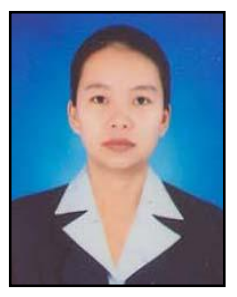

Phatchara Sriphrabu was born in Khon Kaen, Thailand, in 1978. She is Ph.D. student in the Department of Industrial Engineering, Faculty of Engineering, Khon Kaen University, Thailand. She received a master's degree from College of Graduate Study in Management at Khon Kaen University, Thailand in 2005. Her research interests include feasibility study and port management. Her email address is p.sriphrabu@gmail

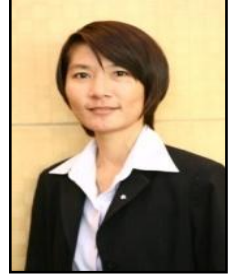

Kanchana Sethanan was born in Khon Kaen, Thailand, in 1969. She is a Lecturer in the Department of Industrial Engineering, Faculty of Engineering, Khon Kaen University, Thailand. She received a Ph.D in Industrial Engineering from West Virginia University, USA in 2001. Her research interests include logistic and supply chain management, scheduling and applied operation research. Her email address is <ksethanan@gmail.com>

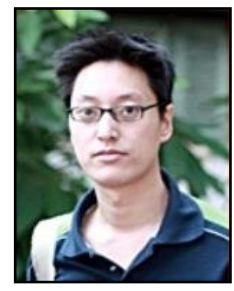

Banchar Arnonkijpanich is an academic staff at Department of Mathematics, Khon Kaen University, Thailand. He received his Master in Computational Science from Chulalongkorn University, Thailand and his Doctorate in Computer Science from Clausthal University of Technology, Germany, in 2003 and 2010, respectively. His research interests include intelligent computing and industrial data analysis. Her email address is < abanchar@kku.ac.th > 